\title{
Development of two components acceleration time histories for Semarang, Indonesia, due to Semarang fault earthquake scenarios using $\mathbf{3 0}$ meters soil deposit model
}

\author{
Windu Partono \\ Civil Engineering Department, Diponegoro University, 50275 Semarang, Indonesia
}

\begin{abstract}
Development of surface acceleration time histories is important for dynamic analysis of structure design and evaluation. Acceleration time histories usually developed from seismograph records due to specific earthquake event. Following the research conducted by Team for Revision of Seismic Hazard Maps of Indonesia 2010 and 2016, Lasem fault and Semarang fault are two closest and dangerous shallow crustal fault earthquake sources which must be taken into account for seismic mitigation of Semarang. This paper presents the development two components surface acceleration time histories for Semarang caused by Semarang fault earthquake scenarios, with magnitude from $6 \mathrm{Mw}$ to $7 \mathrm{Mw}$ and maximum epicentre distance $15 \mathrm{Km}$. This research was performed by conducting deterministic hazard analysis, response spectral matching and site response analysis to obtain a pair of modified acceleration time histories. Site response analysis was performed by conducting 30 meters soil deposit model by taking the assumption that the position of bedrock elevation is 30 meters below the surface layer. Modified acceleration time histories were developed from a pair time histories (North-South/NS and East-West/EW direction) collected from worldwide historical earthquakes. Modified time histories were developed due to limited time histories data caused by Semarang fault earthquake source.
\end{abstract}

\section{Introduction}

Developement of surface acceleration time histories is important for dynamic structure analysis. Acceleration time histories usually developed from seismograph records due to specific earthquake event. Following the research conducted by Team for Revision of Seismic Hazard Maps of Indonesia (TRSHMI) 2010 and 2016, Lasem Fault and Semarang Fault are two closest and dangerous earthquake sources which must be taken into account for seismic hazard and seismic mitigation of Semarang. Lasem fault is a typical strike slip mechanism earthquake source however Semarang fault is a typical reverse mechanism seismic source. To evaluate the hazards of this city, all structure must be designed and evaluated using the ground motion developed from both earthquake sources. This paper presents the development of two components surface acceleration time histories for Semarang caused by Semarang fault earthquake source scenarios, with magnitude from 6 
$\mathrm{Mw}$ to $7 \mathrm{Mw}$ and maximum epicentre distance $15 \mathrm{Km}$. This research was performed by conducting deterministic hazard analysis, response spectral matching and site response analysis at 288 boring locations to obtain two components modified acceleration time histories at surface level.

Site response analysis was performed by conducting 30 meters soil deposit model by taking the assumption that the position of bedrock elevation is 30 meters below the surface layer and the shear wave velocity at bedrock elevation is $760 \mathrm{~m} / \mathrm{s}$. The soil deposit model was implemented following the same research conducted by [1]. This 30 meters model was implemented due to inadequate soil dynamic characteristics data below 30 meter soil elevation until bedrock elevation. Research on predicting bedrock elevation has already performed by [2] using single station feedback seismometer.

Modified acceleration time histories were developed from two components (a pair) time histories (North-South/NS and East-West/EW) directions and collected from worldwide historical earthquakes databases. All acceleration time histories used in this research were collected from worldwide historical earthquakes with similar mechanism to Semarang fault earthquake mechanism. Modified time histories were developed due to inadequate time histories data caused by Semarang Fault earthquake source.

This research was performed by implementing four major steps: 1) conducting geological, geophysical and soil investigation and analysis for developing soil profile, shear wave velocity profile and bedrock elevation 2) collecting a pair of acceleration time histories data (NS and EW) from worldwide historical earthquake records due to reverse mechanism shallow crustal fault source earthquakes with magnitude $6-7 \mathrm{Mw}$ and maximum epicentre distance $15 \mathrm{~km}, 3$ ) developing a pair of modified acceleration time histories by conducting response spectral matching analysis, 4) conducting shear wave propagation analysis using modified acceleration time histories and conducting 30 meters soil deposit model for obtaining surface acceleration time histories and surface spectra acceleration.

\section{Experiment details}

\subsection{Geological and geotechnical investigations}

Following the work conducted by TRSHMI 2010 for updating national seismic hazard maps, Lasem fault and Semarang Fault are two closest and dangerous seismic sources for Semarang. Those two seismic sources were identified to be the main shallow crustal fault source earthquakes that can significantly influence the hazard of the city. Fig. 1(a) shows the position of Semarang and Lasem fault trace.

Soil dynamic parameters of all soil layers above the bedrock elevation and bedrock elevation are two important parameters used for site response analysis. Prediction of bedrock elevation for Semarang was performed using single station feedback Microtremor [2 and 3] by conducting three component ambient vibrations investigation at 218 locations. Fig. 1(b) shows the contour map of bedrock elevation developed from 218 locations. Fig. 2(a) shows microtremor test equipment for bedrock elevation prediction measurements. Based on contour map of bedrock elevation, shear wave velocity test for rock samples were performed by [1] using Ultrasonic Pulse test. The rock samples were collected from soil boring investigations with maximum 40 meters depth. Fig. 1(b) shows five soil boring investigations for verifying bedrock elevation and collecting rock samples for shear wave velocity measurement test. Fig.2(b) shows Ultrasonic Pulse test equipment for predicting shear wave velocity of rock sample. 

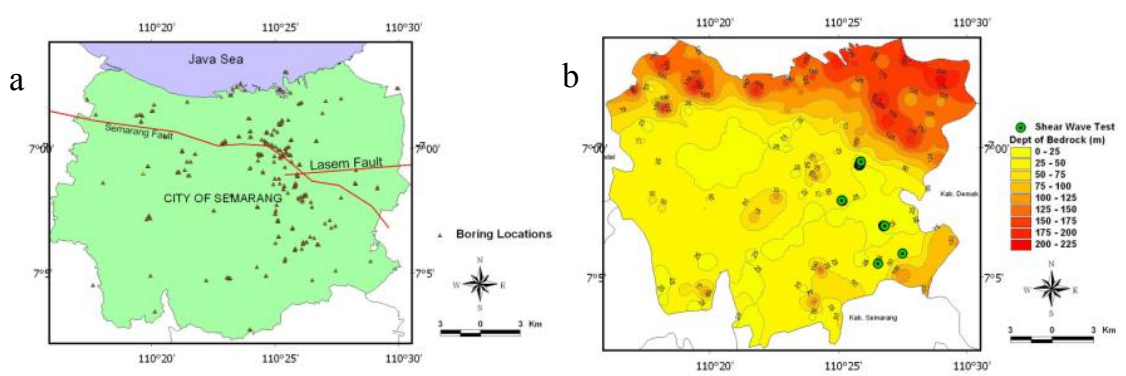

Fig. 1. Semarang fault and Lasem fault trace and boring locations (a) and contour map of bedrock elevation (b).

a

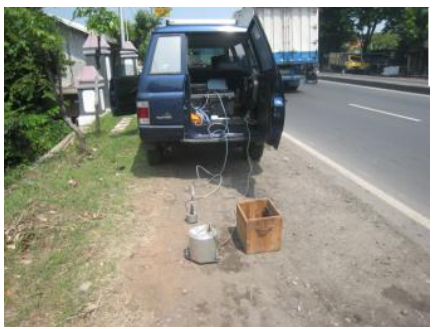

b

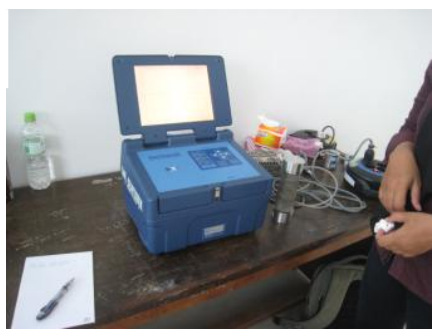

Fig. 2. Microtremor test (a) and Ultrasonic Pulse test (b).

\subsection{Acceleration time histories data collection}

Due to limited earthquake records of Semarang fault earthquake, historical earthquake records with magnitude from 6 to $7 \mathrm{Mw}$ and maximum distance $15 \mathrm{~km}$ were collected from worlwide databases. All acceleration time histories were collected for reverse mechanism shallow crustal fault earthquake events. Five selected earthquakes (Iwate Japan 2008 magnitude 6.9 Mw, Chuetsu-oki Japan 2007 magnitude $6.8 \mathrm{Mw}$, Northridge-01 California 1994 magnitude 6.69 Mw, Chi-Chi Taiwan 1999 magnitude 6.2 Mw and Northridge-02 California 1994 magnitude $6.05 \mathrm{Mw}$ ) were used in this research for site response analysis. All acceleration time histories data (pair of NS and EW directions) were collected from Pasific Earthquake Engineering Research (PEER) NGA-West 2 Databases. Table 1 shows all acceleration time histories from 5 different earthquake events used in this study.

\subsection{Response spectral matching}

All acceleration time histories used in this study need to be matched with the target spectrum of Semarang fault earthquake scenarios. All target response spectrums were developed using deterministic hazard analysis by conducting three different attenuation functions proposed by [4, 5 and 6]. The target spectrums used for spectral matching analysis were predicted at bedrock elevation. All target spectrums were calculated for reverse mechanism shallow crustal fault earthquake sources.

Response spectral matching analysis was conducted following the same method proposed by [7] and producing modified (matched) acceleration time histories. The matched acceleration time histories were predicted using all acceleration time histories (fifteen pairs of N/S and E/W time histories) produced by 5 (five) earthquake events. Initial time histories must have similar shape with matched time histories. Fig. 3(a) shows an example result of spectral matching calculated for Chi-Chi Taiwan (EW direction) with magnitude 6.2 Mw and epicentre distance $5.93 \mathrm{Km}$. Fig.3(b) shows initial and matched 
time histories for Chi-Chi Taiwan (EW direction) with magnitude 6.2 Mw and epicentre distance $5.93 \mathrm{Km}$.

Table 1. Earthquake sources data used in this study.

\begin{tabular}{|c|c|c|c|}
\hline Event & Station & $\mathrm{M}(\mathrm{Mw})$ & $\mathrm{R}(\mathrm{km})$ \\
\hline \multirow{3}{*}{ Northridge-02 (1994) } & Arleta - Nordhoff Fire Sta & 6.05 & 1.48 \\
\cline { 2 - 4 } & Newhall - Fire Sta & 6.05 & 7.36 \\
\cline { 2 - 4 } & LA - Century City CC North & 6.05 & 18.34 \\
\hline \multirow{3}{*}{ Chi-Chi, Taiwan-03 (1999) } & TCU084 & 6.2 & 3.68 \\
\cline { 2 - 4 } & TCU089 & 6.2 & 5.93 \\
\cline { 2 - 4 } & TCU076 & 6.2 & 13.04 \\
\hline \multirow{3}{*}{ Northridge-01 (1994) } & Arleta - Nordhoff Fire Sta & 6.69 & 3.3 \\
\cline { 2 - 4 } & Beverly Hills - 14145 Mulhol & 6.69 & 9.44 \\
\cline { 2 - 4 } & LA - Brentwood VA Hospital & 6.69 & 12.92 \\
\hline \multirow{3}{*}{ Chuetsu - oki, Japan (2007) } & Nagaoka & 6.8 & 3.97 \\
\cline { 2 - 4 } & Kashiwazaki City Takayanagicho & 6.8 & 10.38 \\
\cline { 2 - 4 } & Yan Sakuramachi City Watershed & 6.8 & 12.98 \\
\hline \multirow{3}{*}{ Iwate, Japan (2008) } & IWTH24 & 6.9 & 3.1 \\
\cline { 2 - 4 } & IWT011 & 6.9 & 8.41 \\
\cline { 2 - 4 } & Kurihara City & 6.9 & 12.83 \\
\hline
\end{tabular}

$\mathrm{M}=$ seismic magnitude $\mathrm{R}=$ epicentre distance
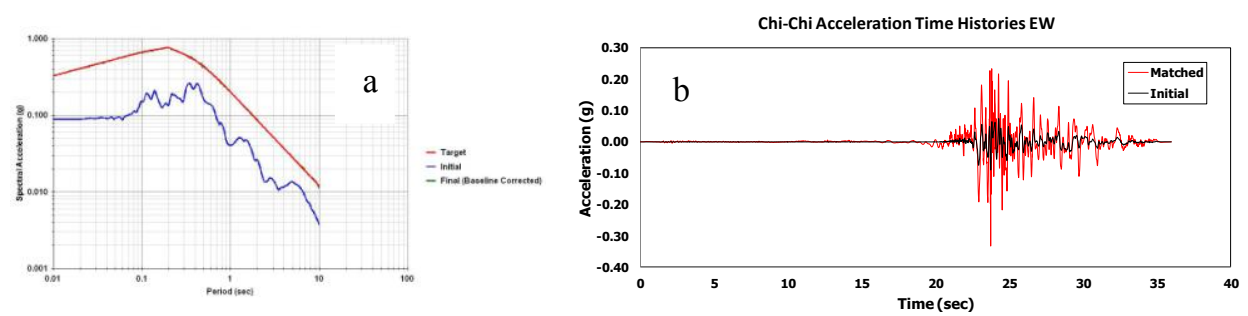

Fig. 3. Spectral matching result (a) and acceleration time histories (initial and matched) EW direction (b) calculated for Chi-Chi Taiwan earthquake $6.2 \mathrm{Mw}$ and epicentre distance $5.93 \mathrm{Km}$.

\subsection{Site response analysis}

Site response analysis was performed at 288 positions for obtaining surface time histories and surface response spectra. Site response analysis due to a specific earthquake was performed using NS and EW matched time histories calculated from spectral matching analysis. Site response analysis was implemented using 30 meters soil deposit model, an alternatif model used to reduce the problems related with soil characteristics data for deep bedrock elevation. Site response analysis was implemented by conducting equation (1) where ' $\rho$ ', 'G' and ' $\eta$ ' are soil density, shear modulus and soil viscosity repectively ([8], [9] and $[10])$.

$$
\rho \frac{\delta^{2} \mathrm{u}}{\delta \mathrm{t}^{2}}=\mathrm{G} \frac{\delta^{2} \mathrm{u}}{\delta \mathrm{z}^{2}}+\eta \frac{\delta^{3} \mathrm{u}}{\delta \mathrm{z}^{2} \delta \mathrm{t}}
$$

As it can be seen on Fig. 1(b) the bedrock elevation on the center and northern part of the study area were predicted more than 50 meters depth. For building construction and foundation design, soil boring investigations on the northern part of the study area usually performs until 60 meters depth. It will be spent alot of time and money to performs boring investigation until more than 200 meters depth. To reduce the problems related with soil properties for deep bedrock elevation, site response analysis in this study was performed 
using 30 meters soil profile model. Fig. 4 shows 30 meters soil profile model used for site response analysis.

To obtain surface spectra acceleration which can be used for structural dynamic analysis, two spectra acceleration (SA) EW direction and NS direction should be modified to produce $\mathrm{SA}_{\text {total }}$. $\mathrm{SA}_{\text {total }}$ can be calculated using equation (2) (Goleshorki, R. 2013 [11]) where $\mathrm{SA}_{\mathrm{EW}}$ and $\mathrm{SA}_{\mathrm{NS}}$ are two spectra acceleration (EW and NS directions) calculated from two acceleration time histories EW and NS directions,

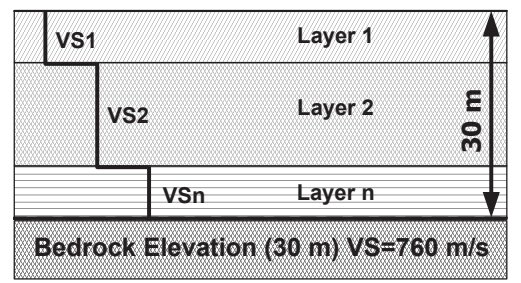

Fig. 4. Soil profile model for site response analysis.

$$
\mathrm{SA}_{\text {total }}=\sqrt{\mathrm{SA}_{\mathrm{EW}}^{2}+\mathrm{SA}_{\mathrm{NE}}^{2}}
$$

\section{Results and discussions}

Based on response spectral matching and site response analysis conducting for fifteen acceleration time histories, fifteen pair (NS and EW directions) surface acceleration time histories were developed for this study area. All fifteen pair surface acceleration time histories can be used for dynamic analysis of structures. Fig. 5 shows two examples surface acceleration time histories (EW and NS directions) developed from Northridge-01 earthquake event with magnitude $6.69 \mathrm{Mw}$ and epicentre distance $3.3 \mathrm{Km}$. Fig. 6 shows two examples surface acceleration time histories (EW and NS directions) developed from Chi-Chi Taiwan earthquake with magnitude $6.2 \mathrm{Mw}$ and epicentre distance $3.86 \mathrm{Km}$.
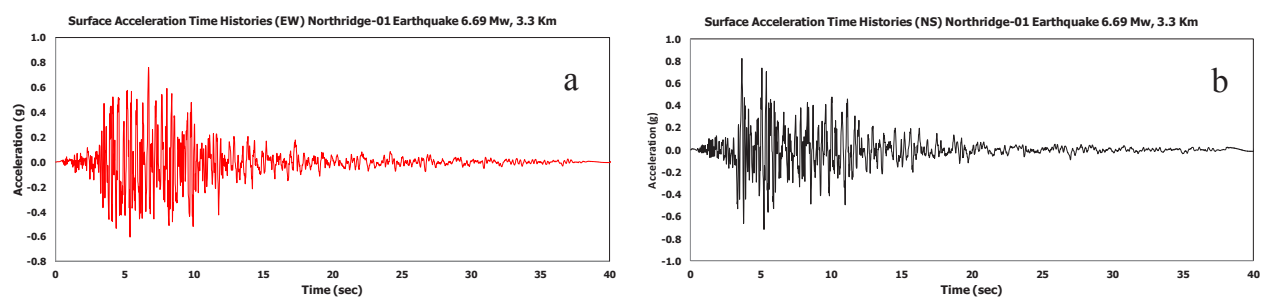

Fig. 5. Surface acceleration time histories EW direction (a) and NS direction (b) for Northridge-01 earthquake with magnitude $6.69 \mathrm{Mw}$ and epicentre distance $3.3 \mathrm{Km}$.
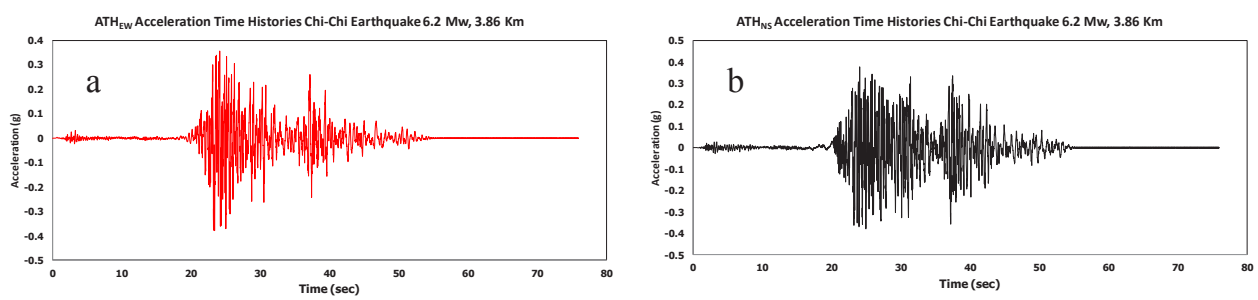

Fig. 6. Surface acceleration time histories EW direction (a) and NS direction (b) for Chi-Chi Taiwan earthquake with magnitude $6.2 \mathrm{Mw}$ and epicentre distance $3.86 \mathrm{Km}$. 


\section{Conclusions}

Two components surface acceleration time histories for Semarang due to Semarang fault earthquake with magnitude from $6.05 \mathrm{Mw}$ to $6.9 \mathrm{Mw}$ and epicentre distance maximum 15 $\mathrm{Km}$ has already developed. All acceleration time histories was developed using 30 meters soil deposit model. The model was implemented to reduce the problems related with soil investigation and soil dynamic parameters at the northern part of the study area. Fifteen pair surface acceleration time histories were developed following two major analysis response spectral matching and site response analysis.

Due to limited information and data related with original or initial acceleration time histories caused by Semarang fault earthquake all acceleration time histories were collected from PEER NGA-West 2 Databases. Five selected earthquakes (Iwate Japan 2008 magnitude 6.9 Mw, Chuetsu-oki Japan 2007 magnitude 6.8 Mw, Northridge 01 California 1994 magnitude 6.69 Mw, Chi-Chi Taiwan 1999 magnitude 6.2 Mw and Northridge 02 California 1994 magnitude $6.05 \mathrm{Mw}$ ) can be used for structural dynamic analysis and design for the study area.

\section{References}

1. W. Partono, Seismic Microzonation Map Design for Semarang City by Developing Seismic Hazard Program and Adjusting Building Fragility Condition, Doctor Disertation Civil Engineering Department Diponegoro University, (2015)

2. S.P.R. Wardani, M. Irsyam, W. Partono and S. Maarif, Bedrock elevation measurement using ambient vibrationsand ultra-sonic pulse test, Geotechnics for Castratophic Flooding Events - iai (ed), Taylor and Francis Group, London, (2015)

3. W. Partono, S.P.R. Wardani, M. Irsyam and S. Maarif, "Development of seismic microzonation maps of Semarang, Indonesia, Jurnal Teknologi”, 77:11, 99-107 (2015)

4. D.M. Boore and G.M. Atkinson, Earthq. Spec., Vol. 24, No. 1, 99-138, Earthq. Eng. Res. Inst. (2008)

5. K.W. Campbell and Y. Bozorgnia, Earthq. Spec., Vol. 24, No. 1, 139-171, Earthq. Eng. Res. Inst. (2008)

6. B.S.J. Chiou and R.R. Youngs, NGA Model for Average Horizontal Component of Peak Ground Motion and Response Spectra, (PEER 2008/09, Pacific Engineering Research Centre, College of Engineering, University of California, Berkeley, 2008)

7. N.A. Abrahamson, Non Stationary Spectral Matching Program RSPMATCH $>P G \& E$, (Internal Report, 1998)

8. W.D. Iwan, On a Class of Models for the Yielding Behaviour of Continuous and Composite Systems, (Journal of Applied Mechanics, ASME, 34, New York, 1967), 612-617

9. Z. Mroz, On the Description of Anisotropic Work Hardening, (Journal of Mechanics and Physics of Solids, 15, Elsevier, Rhode Island USA, 1967), 163-175

10. J.P. Bardet and T. Tobita, NERA A Computer Program for Nonlinear Earthquake Site Response Analysis of Layered Soil Deposits, (Department of Civil Engineering University of Southern California, 2001)

11. I.W. Sengara, M.A. Yulman and A. Mulia, "Seismic Time-History Ground-Motions for a specific Site in Jakarta, Jurnal Teknologi”, 77:21, 127-136 (2015) 